\title{
Temperature dependence of spectral characteristics of distributed feedback resonators
}

Kores, C., Ismail, N., Geskus, D., Dijkstra, M., Bernhardi, E., et al.

C. C. Kores, N. Ismail, D. Geskus, M. Dijkstra, E. H. Bernhardi, M. Pollnau, "Temperature dependence of spectral characteristics of distributed feedback resonators," Proc. SPIE 10683, Fiber Lasers and Glass Photonics: Materials through Applications, 106830B (17 May 2018); doi: 10.1117/12.2307023

SPIE. Event: SPIE Photonics Europe, 2018, Strasbourg, France 


\title{
Temperature Dependence of Spectral Characteristics of Distributed-Feedback Resonators
}

\author{
C. C. Kores ${ }^{\mathrm{a}}$, N. Ismail ${ }^{\mathrm{a}}$, D. Geskus ${ }^{\mathrm{a}}$, M. Dijkstra ${ }^{\mathrm{b}}$, E. H. Bernhardi ${ }^{\mathrm{a}, \mathrm{c}}$, M. Pollnau*a,d \\ a'Department of Materials and Nano Physics, KTH-Royal Institute of Technology, 16440 Kista,

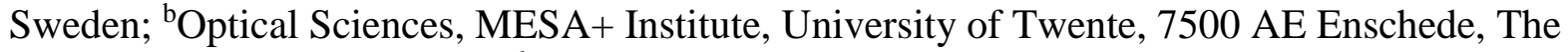 \\ Netherlands; 'Visiting scientist; ${ }^{\mathrm{d}}$ Advanced Technology Institute, University of Surrey, Guildford \\ GU2 7XH, United Kingdom
}

\begin{abstract}
The spectral response of a distributed-feedback resonator with a thermal chirp is investigated. $\mathrm{An} \mathrm{Al}_{2} \mathrm{O}_{3}$ channel waveguide with a surface Bragg grating inscribed into its $\mathrm{SiO}_{2}$ top cladding is studied. A linear temperature gradient along the resonator leads to a corresponding variation of the grating period. We characterize its spectral response with respect to wavelength and linewidth changes of the resonance peak. Simulated results show good agreement with the experimental data, indicating that the resonance wavelength is determined by the total accumulated phase shift. The calculated grating reflectivities at the resonance wavelength largely explain the observed changes of the resonance linewidth. This agreement demonstrates that the linewidth increase is caused by the increase of resonator outcoupling losses.
\end{abstract}

Keywords: Distributed-feedback laser; Bragg grating; Thermal grating chirp; Resonance wavelength; Resonance linewidth

\section{INTRODUCTION}

Periodic corrugated structures have been extensively investigated over the past four decades, for their significant and wide range of applications, being employed as spectral filters [1,2], temperature and strain sensors [3], couplers [4], beam splitters, as well as part of the resonant structure in distributed-feedback (DFB) [5] and distributed-Bragg-reflector (DBR) lasers, which can be employed for microwave beat-signal generation [6] and optical sensing $[7,8]$. DFB and DBR lasers relies on the fact that the Bragg grating provides very high wavelength selectivity [9], hence allowing for the development of ultranarrow-linewidth lasers [10-15]. The grating period has a strong influence on the longitudinal-mode selectivity [16-18]. Gratings with non-uniform period (chirped gratings) have received much interest [19-21], and substantial attention has been paid to the design of chirped gratings that manipulate the intracavity power distribution and avoid spatial hole burning in DFB lasers [22-24].

Rare-earth-doped amplifiers [25-30] and lasers [31-33] in amorphous materials can be integrated on a silicon chip [34] and combined with other materials, such as silicon-on-insulator [35] or polymer [36] waveguides. Although the gain per unit length can be significantly higher in crystalline materials, up to $1000 \mathrm{~dB} / \mathrm{cm}$ [37], whereas amorphous materials suffer from inhomogeneous linewidth broadening and quenching processes [38,39], overcoming the losses is sufficient to achieve efficient lasing [40]. However, despite careful design of DFB resonators for ultranarrow-linewidth laser operation, optically pumped DFB lasers [41] exhibit asymmetric heating due to non-uniformly absorbed pump power, which is partially converted into heat and may, therefore, cause an undesired chirp in the Bragg structure [42]. The resulting changes in refractive index as well as material expansion influence the resonance frequency and linewidth of the central emission line. Thermally induced chirped gratings are reported in the literature under the scope of power stability and spectral response [43-49], however, to the best of our knowledge, a complete and satisfactory explanation of the relationship between the chirped grating profile and the linewidth produced by the resonator is still lacking.

We investigate the spectral characteristics of DFB resonators with a thermally induced chirp in their Bragg grating [42]. A temperature gradient with an approximately linear profile is experimentally produced along the waveguide resonator, and the wavelength of the resonance peak and its linewidth are characterized. The experimental results show good agreement with simulations based on Born and Wolf's [50] characteristic-matrix approach.

*m.pollnau@surrey.ac.uk

Fiber Lasers and Glass Photonics: Materials through Applications, edited by

Stefano Taccheo, Jacob I. Mackenzie, Maurizio Ferrari, Proc. of SPIE Vol. 10683

106830B - (c) 2018 SPIE · CCC code: 0277-786X/18/\$18 - doi: 10.1117/12.2307023 


\section{EXPERIMENTAL}

The sample investigated in this work is an amorphous $\mathrm{Al}_{2} \mathrm{O}_{3}: \mathrm{Yb}^{3+}$ rib waveguide with an $\mathrm{Yb}^{3+}$ concentration of $4.37 \times$ $10^{20} \mathrm{~cm}^{-3}$, deposited by $\mathrm{RF}$ reactive co-sputtering from metallic $\mathrm{Al}$ and $\mathrm{Yb}$ targets onto a thermally oxidized silicon wafer [51]. $\mathrm{Al}_{2} \mathrm{O}_{3}$ can be micro-structured in various ways, e.g. by focused-ion-beam etching [52], $\mathrm{Ar}^{+}$milling [53], or reactive ion etching [54]. Here we used chlorine-based reactive ion etching [55]. The rib waveguide has a length of $\ell=1 \mathrm{~cm}$ and $2.5 \times 1.0 \mu \mathrm{m}^{2}$ lateral cross section, designed to support only fundamental-transverse-mode propagation. The refractive index of the layer depends on the dopant concentration [56]. $\mathrm{A} \mathrm{SiO}_{2}$ top cladding of $350 \mathrm{~nm}$ thickness was added. A corrugated homogeneous Bragg grating, where $\kappa=8.33 \mathrm{~cm}^{-1}$ is the grating coupling coefficient per unit length [13], is inscribed into the $\mathrm{SiO}_{2}$ top cladding by laser interference lithography and subsequent reactive ion etching [12,13], providing the necessary feedback for single-longitudinal-mode laser operation at the Bragg wavelength $\lambda_{B}$ [57]. The propagation losses are $0.20 \mathrm{~dB} / \mathrm{cm}$ and the $\mathrm{Yb}^{3+}$ absorption losses are $0.33 \mathrm{~dB} / \mathrm{cm}$ [58], resulting in a sum of propagation and absorption losses of $0.53 \mathrm{~dB} / \mathrm{cm}$.

The $\lambda_{B} / 4$ phase shift required for producing a resonance within the reflection band of the Bragg grating is achieved by an adiabatic tapering of the waveguide structure [59,12], in which the waveguide width first increases and then decreases gradually according to a $\sin ^{2}$ function from 2.5 to $2.85 \mu \mathrm{m}$ over a total length of $2 \mathrm{~mm}$. As a consequence, the effective refractive index to which the propagating mode is subject also increases with the same function. The tapered section of the waveguide is designed to result in an accumulated phase shift of $\lambda_{B} / 4$. The phase-shift region is centered at the position $z_{p s}=7 \mathrm{~mm}$ in order to yield higher output powers in one direction $[60,12]$. Having introduced the tapering of the waveguide, the resultant modulation of the refractive index is no longer periodic, and therefore the Bragg grating becomes non-periodic.

We generate a temperature gradient by controlling the temperature in the sample holder along the waveguide direction. The temperature on the top surface of the sample holder is measured using a thermocouple sensor, in several positions along the surface where the waveguide is to be placed. The temperature along the waveguide is fitted by a linear function, from which the temperature at the center of the phase shift is estimated.

The approximately Lorentzian-shaped resonance near $1028.25 \mathrm{~nm}$ is measured in the unpumped sample, and the peak wavelength and full-width-at-half-maximum (FWHM) linewidth of the resonance are characterized, providing information about the behavior of light inside the optical resonator [61]. As a probe beam, the signal from a scanning narrow-linewidth laser centered at $1028.25 \mathrm{~nm}$ is fiber-coupled to the waveguide. The transmitted light is collected by an optical fiber, discriminated from residual room light by a monochromator, and detected by a photomultiplier tube. This setup enabled measurement of the spectral response of the resonator for the temperature profiles produced along the waveguide, which result in thermally induced chirp profiles of the grating period. The FWHM of $40 \mathrm{MHz}$ of the scanning narrow-linewidth laser is considered to de-convolute the measurement and obtain the correct line shape of the resonance, to which a Lorentzian curve is fitted to derive the FWHM linewidth. Although the temperature dependence of transition cross sections in laser systems can be significant $[62,63]$, the absorption losses and the waveguide propagation losses remain approximately constant for the temperature range investigated here.

The experiments are complemented by calculations and simulations [42], see also [5,64-68].

\section{RESULTS AND DISCUSSIONS}

Although the spectral profiles are symmetric in the frequency domain [69], we choose the wavelength domain for investigation, as the wavelength range over which the analysis is carried out is small enough to result in negligible asymmetry of the spectral profiles. Under uniform heating of the sample, the dependence of wavelength shift of the resonance peak with temperature is approximately linear and amounts to $12.0 \mathrm{pm} / \mathrm{K}$ for $\sim 1028 \mathrm{~nm}$, i.e., a relative wavelength shift of $\sim 1.2 \times 10^{-5} \mathrm{~K}^{-1}$, which is in reasonable agreement with the values of $19 \pm 1 \mathrm{pm} / \mathrm{K}[13]$ and $20 \mathrm{pm} / \mathrm{K}$ [70] reported for $\sim 1560-1590 \mathrm{~nm}$, therefore corresponding to the same relative wavelength shift. From the shift of peak wavelength with temperature, we derive a change of refractive index with temperature of $d n / d T=1.86 \times 10^{-5} \mathrm{~K}^{-1}$. Since part of the shift is due to sample expansion, this value represents an upper limit to the refractive index change with temperature. The value is higher than the corresponding value of $0.83 \times 10^{-5} \mathrm{~K}^{-1}$ in $\mathrm{Y}_{3} \mathrm{Al}_{5} \mathrm{O}_{12}$ and the absolute of the two 
values of $-0.43 \times 10^{-5} \mathrm{~K}^{-1}$ and $-0.20 \times 10^{-5} \mathrm{~K}^{-1}$ for the $c$ - and $a$-axes, respectively, in $\mathrm{YLiF}_{4}$ (see Ref. [71] and Refs. therein), but smaller than the value of $4.58 \times 10^{-5} \mathrm{~K}^{-1}$ previously reported for amorphous $\mathrm{Al}_{2} \mathrm{O}_{3}$ [72].

The reflectivity profiles of grating 1 and grating 2 were simulated for the different values of linear chirp coefficient $\delta_{\text {lin }}$. We obtain the reflectivity spectra of both gratings and the resulting Lorentzian-shaped resonance from the same simulation, enabling us to place the resonance within the reflection band of the gratings. The transmission spectrum is obtained by considering also the absorption and propagation losses. The resonance wavelength shifts linearly toward larger values for increasing values of $\delta_{l i n}$, which is a consequence of the linear increase in the accumulated phase shift. The reflection band changes drastically when the chirped profiles are imposed on the grating. This is a result of the change in the individual spectral responses provided by gratings 1 and 2 . The spectral profile of the resonance is obtained experimentally for the temperature profiles produced. Each resonance peak is fitted by a Lorentzian function and both are simultaneously normalized such that the peak value of the Lorentzian function is unity.

The simulation results indicate that the resonance wavelength is mostly a result of the grating-period value at the phaseshift center, whereas the additional wavelength shift resulting from the grating chirp is small. Since the increase in grating period at the phase-shift center is proportional to $\delta_{\text {lin }}$, the shift of resonance wavelength is a linear function of $\delta_{l i n}$. The measured values of resonance wavelength also exhibit a linear dependence on the estimated temperature at the phase-shift center.

The resonance linewidth is due to the outcoupling, propagation, and absorption losses. Imposing a chirp in the grating period changes the refractive index, the resonator length and, consequently, the round-trip time. All three losses depend on the refractive index. However, the change in refractive index is small, hence its effect is negligible. The propagation and absorption losses are defined per unit length, hence are independent of the resonator length. Moreover, for a temperature increase of a few degrees, they remain approximately constant. Consequently, their influence on the linewidth is also negligible. In contrast, the mirror reflectivites change significantly with a few degrees of temperature change, causing the linewidth to increase. The resonance linewidth changes approximately linearly as a function of grating reflectivities [42].

\section{CONCLUSIONS}

We have investigated the spectral response of a DFB rib waveguide resonator experimentally and by simulations. For uniform heating of the sample, the FWHM linewidth of the Lorentzian-shaped resonance remained unchanged. When a linear chirp profile was produced in the grating period, the FWHM linewidth increased. The outcoupling, propagation, and absorption losses are the parameters responsible for the FWHM linewidth of the resonance. We have demonstrated that the increase in the outcoupling losses is largely responsible for the increase in the FWHM linewidth of the resonance.

\section{REFERENCES}

[1] Limberger, H. G., Ky, N. H., Costantini, D. M., Salathé, R. P., Muller, C. A. P. and Fox, G. R., "Efficient miniature fiber optic tunable filter based on intra-core Bragg grating and electrically resistive coating," IEEE Photon. Technol. Lett. 10(3), 361-363 (1998).

[2] Costantini, D. M., Limberger, H. G., Salathé, R. P., Muller, C. A. P. and Vasiliev, S. A., "Tunable loss filter based on metal coated long period fiber grating," IEEE Photon. Technol. Lett. 11(11), 1458-1460 (1999).

[3] Meltz, G., Dunphy, J. R., Glenn, W. H., Farina, J. D. and Leonberger, F. J., "Fiber optic temperature and strain sensors," Proc. SPIE 798, 104-114 (1987).

[4] Dakss, M. L., Kuhn, L., Heidrich, P. F. and Scott, B. A., "Grating coupler for efficient excitation of optical guided waves in thin films," Appl. Phys. Lett. 16(12), 523-525 (1970).

[5] Kogelnik, H. and Shank, C. V., "Coupled-wave theory of distributed feedback lasers," J. Appl. Phys. 43(5), 2327-2335 (1972).

[6] Bernhardi, E. H., Khan, M. R. H., Roeloffzen, C. G. H., van Wolferen, H. A. G. M., Wörhoff, K., de Ridder, R. M. and Pollnau, M., "Photonic generation of stable microwave signals from a dual-wavelength $\mathrm{Al}_{2} \mathrm{O}_{3}: \mathrm{Yb}^{3+}$ distributed-feedback waveguide laser," Opt. Lett. 37(2), 181-183 (2012). 
[7] Pham, S. V., Dijkstra, M., Hollink, A. J. F., Kauppinen, L. J., de Ridder, R. M., Pollnau, M., Lambeck, P. V. and Hoekstra, H. J. W. M., "On-chip bulk-index concentration and direct, label-free protein sensing utilizing an optical grated-waveguide cavity," Sens. Actuator B 174, 602-608 (2012).

[8] Bernhardi, E. H., van der Werf, K. O., Hollink, A. J. F., Wörhoff, K., de Ridder, R. M., Subramaniam, V. and Pollnau, M., "Intra-laser-cavity microparticle sensing with a dual-wavelength distributed-feedback laser," Laser Photonics Rev. 7(4), 589-595 (2013).

[9] Chung, T.-Y., Rapaport, A., Smirnov, V., Glebov, L. B., Richardson, M. C. and Bass, M., "Solid-state laser spectral narrowing using a volumetric photothermal refractive Bragg grating cavity mirror," Opt. Lett. 31(2), 229-231 (2006).

[10] Ball, G. A., Morey, W. W. and Glenn, W. H., "Standing-wave monomode erbium fiber laser," IEEE Photon. Technol. Lett. 3(7), 613-615 (1991).

[11] Blaize, S., Bastard, L., Cassagnetes, C. and Broquin, J. E., "Multiwavelengths DFB waveguide laser arrays in Yb-Er codoped phosphate glass substrate," IEEE Photon. Technol. Lett. 15(4), 516-518 (2003).

[12] Bernhardi, E. H., van Wolferen, H. A. G. M., Agazzi, L., Khan, M. R. H., Roeloffzen, C. G. H., Wörhoff, K., Pollnau, M. and de Ridder, R. M., "Ultra-narrow-linewidth, single-frequency distributed feedback waveguide laser in $\mathrm{Al}_{2} \mathrm{O}_{3}$ : $\mathrm{Er}^{3+}$ on silicon," Opt. Lett. 35(14), 2394-2396 (2010).

[13] Bernhardi, E. H., Lu, Q., van Wolferen, H. A. G. M., Wörhoff, K., de Ridder, R. M. and Pollnau, M., "Monolithic distributed Bragg reflector cavities in $\mathrm{Al}_{2} \mathrm{O}_{3}$ with quality factors exceeding $10^{6}$," Photon. Nanostruct. 9(3), 225-234 (2011).

[14] Purnawirman, Sun, J., Adam, T. N., Leake, G., Bradley, J. D. B., Hosseini, E. S. and Watts, M. R., "C- and Lband erbium-doped waveguide lasers with wafer-scale silicon nitride cavities," Opt. Lett. 38(11), 1760-1762 (2013).

[15]Belt, M., Huffman, T., Davenport, M. L., Li, W., Barton, J. S. and Blumenthal, D. J., "Arrayed narrow linewidth erbium-doped waveguide-distributed feedback lasers on an ultra-low-loss silicon-nitride platform," Opt. Lett. 38(22), 4825-4828 (2013).

[16] Suzuki, A. and Tada, K., "Theory and experiment on distributed feedback lasers with chirped grating," Proc. SPIE 0239, 10-18 (1980).

[17]Zhou, P. and Lee, G. S., "Mode selection and spatial hole burning suppression of a chirped grating distributed feedback laser," Appl. Phys. Lett. 56(15), 1400-1402 (1990).

[18] Hillmer, H., Grabmeier, A., Hansmann, S. and Burkhard, H., "Continuously distributed phase shifts in chirped DFB lasers using bent waveguides," Electron. Lett. 30(18), 1483-1484 (1994).

[19]Livanos, Y. A. C., Katzir, A. and Yariv, A., "Fabrication of grating structures with variable period," Opt. Commun. 20(1), 179-182 (1977).

[20] Katzir, A., Livanos, A., Shellan, J. and Yariv, A., "Chirped gratings in integrated optics," IEEE J. Quantum Electron. 13(4), 296-304 (1977).

[21] Chen, N., Nakano, Y., Okamoto, K., Tada, K., Morthier, G. I. and Baets, R. G., "Analysis, fabrication, and characterization of tunable DFB lasers with chirped gratings," IEEE J. Sel. Top. Quantum Electron. 3(2), 541-546 (1997).

[22] Agrawal, G. P., Geusic, J. E. and Anthony, P. J., "Distributed feedback lasers with multiple phase-shift regions," Appl. Phys. Lett. 53(3), 178-179 (1988).

[23]Zhou, P. and Lee, G. S., "Chirped grating $\lambda / 4$ shifted DFB laser with uniform longitudinal field distribution," Electron. Lett. 26(20), 1660-1661 (1990).

[24] Okai, M., Tsuchiya, T., Uomi, K., Chinone, N. and Harada, T., "Corrugation-pitch modulated MQW-DFB lasers with narrow spectral linewidth,” IEEE J. Quantum Electron. 27(6), 1767-1772 (1991).

[25] Yang, J., Diemeer, M.B.J., Geskus, D., Sengo, G., Pollnau, M. and Driessen, A., "Neodymium-complex-doped photodefined polymer channel waveguide amplifiers," Opt. Lett. 34(4), 473-475 (2009).

[26] Yang, J., Diemeer, M.B.J., Sengo, G., Pollnau, M. and Driessen, A., "Nd-doped polymer waveguide amplifiers,” IEEE J. Quantum Electron. 46(7), 1043-1050 (2010).

[27] Bradley, J. D. B., Agazzi, L., Geskus, D., Ay, F., Wörhoff, K. and Pollnau, M., "Gain bandwidth of $80 \mathrm{~nm}$ and $2 \mathrm{~dB} / \mathrm{cm}$ peak gain in $\mathrm{Al}_{2} \mathrm{O}_{3}: \mathrm{Er}^{3+}$ optical amplifiers on silicon,” J. Opt. Soc. Am. B 27(2), 187-196 (2010).

[28] Bradley, J. D. B., Costa e Silva, M., Gay, M., Bramerie, L., Driessen, A., Wörhoff, K., Simon, J. C. and Pollnau, M., "170 GBit/s transmission in an erbium-doped waveguide amplifier on silicon," Opt. Express 17(24), 22201-22208 (2009). 
[29] Vázquez-Córdova, S. A., Dijkstra, M., Bernhardi, E. H., Ay, F., Wörhoff, K., Herek, J. L., García-Blanco, S. M. and Pollnau, M., "Erbium-doped spiral amplifiers with $20 \mathrm{~dB}$ of net gain on silicon," Opt. Express 22(21), 25993-26004 (2014).

[30] Yang, J., van Dalfsen, K., Wörhoff, K., Ay, F. and Pollnau, M., "High-gain $\mathrm{Al}_{2} \mathrm{O}_{3}$ :Nd ${ }^{3+}$ channel waveguide amplifiers at $880 \mathrm{~nm}, 1060 \mathrm{~nm}$, and $1330 \mathrm{~nm}$," Appl. Phys. B 101(1-2), 119-127 (2010).

[31] Yang, J., Diemeer, M.B.J., Grivas, C., Sengo, G., Driessen, A., and Pollnau, M., "Steady-state lasing in a solid polymer," Laser Phys. Lett. 7(9), 650-656 (2010).

[32] Grivas, C., Yang, J., Diemeer, M.B.J., Driessen, A., and Pollnau, M., “Continuous-wave Nd-doped polymer lasers," Opt. Lett. 35(12), 1983-1985 (2010).

[33] Bradley, J. D. B., Stoffer, R., Agazzi, L., Ay, F., Wörhoff, K. and Pollnau, M., "Integrated $\mathrm{Al}_{2} \mathrm{O}_{3}: \mathrm{Er}^{3+}$ ring laser on silicon with wide wavelength selectivity," Opt. Lett. 35(1), 73-75 (2010).

[34] Pollnau, M., "Rare-earth-ion-doped channel waveguide lasers on silicon,” IEEE J. Sel. Top. Quantum Electron. 21(1), 1602512 (2015).

[35] Agazzi, L., Bradley, J. D. B., Dijkstra, M., Ay, F., Roelkens, G., Baets, R., Wörhoff, K. and Pollnau, M., "Monolithic integration of erbium-doped amplifiers with silicon-on-insulator waveguides," Opt. Express 18(26), 27703-27711 (2010).

[36] Yang, J., Lamprecht, T., Wörhoff, K., Driessen, A., Horst, F., Offrein, B. J., Ay, F. and Pollnau, M., "Integrated optical backplane amplifier," IEEE J. Sel. Top. Quantum Electron. 17(3), 609-616 (2011).

[37] Geskus, D., Aravazhi, S., García-Blanco, S. M. and Pollnau, M., "Giant optical gain in a rare-earth-ion-doped microstructure," Adv. Mater. 24(10), OP19-OP22 (2012).

[38] Agazzi, L., Wörhoff, K. and Pollnau, M., "Energy-transfer-upconversion models, their applicability and breakdown in the presence of spectroscopically distinct ion classes: A case study in amorphous $\mathrm{Al}_{2} \mathrm{O}_{3}: \mathrm{Er}^{3+}$, , J. Phys. Chem. C 117(13), 6759-6776 (2013).

[39]Loiko, P. and Pollnau, M., "Stochastic model of energy-transfer processes among rare-earth ions. Example of $\mathrm{Al}_{2} \mathrm{O}_{3}: \mathrm{Tm}^{3+}$," J. Phys. Chem. C 120(46), 26480-26489 (2016).

[40] Agazzi, L., Bernhardi, E. H., Wörhoff, K. and Pollnau, M., "Impact of luminescence quenching on relaxationoscillation frequency in solid-state lasers," Appl. Phys. Lett. 100(1), 011109 (2012).

[41] Pollnau, M. and Bradley, J. D. B., “Optically pumped distributed-feedback lasers,” Opt. Express, submitted (2018).

[42] Kores, C. C., Ismail, N., Geskus, D., Dijkstra, M., Bernhardi, E. H. and Pollnau, M., "Temperature dependence of the spectral characteristics of distributed-feedback resonators," Opt. Express 26(4), 4892-4905 (2018).

[43]Lauzon, J., Thibault, S., Martin, J. and Ouellette, F., "Implementation and characterization of fiber Bragg gratings linearly chirped by a temperature gradient," Opt. Lett. 19(23), 2027-2029 (1994).

[44] Rogers, J. A., Eggleton, B. J., Jackman, R. J., Kowach, G. R. and Strasser, T. A., "Dual on-fiber thin-film heaters for fiber gratings with independently adjustable chirp and wavelength," Opt. Lett. 24(19), 1328-1330 (1999).

[45] Ngo, N. Q., Liu, D., Tjin, S. C., Dong, X. Y. and Shum, P., “Thermally switchable and discretely tunable comb filter with a linearly chirped fiber Bragg grating," Opt. Lett. 30(22), 2994-2996 (2005).

[46] Dai, Y. T. and Yao, J. P., "Numerical study of a DFB semiconductor laser and laser array with chirped structure based on the equivalent chirp technology," IEEE J. Quantum Electron. 44(10), 938-945 (2008).

[47] Marshall, G. D., Williams, R. J., Jovanovic, N., Steel, M. J. and Withford, M. J., "Point-by-point written fiber Bragg gratings and their applications in complex grating designs," Opt. Express 18(19), 19844-19859 (2010).

[48] Miller, G. A., Peele, J. R., Askins, C. G. and Cranch, G. A., "Characterization of strong fiber Bragg gratings using an applied thermal chirp and iterative algorithm," Appl. Opt. 50(36), 6617-6626 (2011).

[49] Tjörnhammar, S., Jacobsson, B., Pasiskevicius, V. and Laurell, F., "Thermal limitations of volume Bragg gratings used in lasers for spectral control," J. Opt. Soc. Am. B 30(6), 1402-1409 (2013).

[50] Born, M. and Wolf, E., Principles of Optics, Pergamon, Chap. 1 (1975).

[51] Wörhoff, K., Bradley, J. D. B., Ay, F., Geskus, D., Blauwendraat, T. P. and Pollnau, M., "Reliable low-cost fabrication of low-loss $\mathrm{Al}_{2} \mathrm{O}_{3}: \mathrm{Er}^{3+}$ waveguides with 5.4-dB optical gain,” IEEE J. Quantum Electron. 45(5), 454-461 (2009).

[52] Ay, F., Wörhoff, K., de Ridder, R. M. and Pollnau, M., "Focused-ion-beam nano-structuring of $\mathrm{Al}_{2} \mathrm{O}_{3}$ dielectric layers for photonic applications,” J. Micromech. Microeng. 22(10), 105008 (2012). 
[53] Grivas, C., Shepherd, D. P., May-Smith, T. C., Eason, R. W., Pollnau, M., Crunteanu, A. and Jelinek, M., "Performance of $\mathrm{Ar}^{+}$-milled Ti:Sapphire rib waveguides as single transverse-mode broadband fluorescence sources," IEEE J. Quantum Electron. 39(3), 501-507 (2003).

[54] Crunteanu, A., Pollnau, M., Jänchen, G., Hibert, C., Hoffmann, P., Salathé, R. P., Eason, R. W., Grivas, C. and Shepherd, D. P., "Ti:sapphire rib channel waveguide fabricated by reactive ion etching of a planar waveguide," Appl. Phys. B 75(1), 15-17 (2002).

[55] Bradley, J. D. B., Ay, F., Wörhoff, K. and Pollnau, M., "Fabrication of low-loss channel waveguides in $\mathrm{Al}_{2} \mathrm{O}_{3}$ and $\mathrm{Y}_{2} \mathrm{O}_{3}$ layers by inductively coupled plasma reactive ion etching," Appl. Phys. B 89(2-3), 311-318 (2007).

[56] Loiko, P., Ismail, N., Bradley, J. D. B., Götelid, M. and Pollnau, M., "Refractive-index variation with rare-earth incorporation in amorphous $\mathrm{Al}_{2} \mathrm{O}_{3}$ thin films," J. Non-Cryst. Sol. 476, 95-99 (2017).

[57] Bernhardi, E. H., van Wolferen, H. A. G. M., Wörhoff, K., de Ridder, R. M. and Pollnau, M., "Highly efficient, low-threshold monolithic distributed-Bragg-reflector channel waveguide laser in $\mathrm{Al}_{2} \mathrm{O}_{3}: \mathrm{Yb}^{3+}$," Opt. Lett. 36(5), 603-605 (2011).

[58] Agazzi, L., "Spectroscopic excitation and quenching processes in rare-earth-ion-doped $\mathrm{Al}_{2} \mathrm{O}_{3}$ and their impact on amplifier and laser performance," Ph.D. thesis, University of Twente, The Netherlands (2012).

[59] Tada, K., Nakano, Y. and Ushirokawa, A., "Proposal of a distributed feedback laser with nonuniform stripe width for complete single-mode oscillation," Electron. Lett. 20(2), 82-84 (1984).

[60] Usami, M., Akiba, S. and Utaka, K., “Asymmetric $\lambda / 4$-shifted InGaAsP/InP DFB lasers," IEEE J. Quantum Electron. 23(6), 815-821 (1987).

[61] Soda, H. and Imai, H., "Analysis of the spectrum behavior below the threshold in DFB lasers," IEEE $J$. Quantum Electron. 22(5), 637-641 (1986).

[62] Eichhorn, M., Fredrich-Thornton, S. T., Heumann, E. and Huber, G., "Spectroscopic properties of Er ${ }^{3+}: Y A G$ at 300-550 K and their effects on the $1.6 \mu \mathrm{m}$ laser transition," Appl. Phys. B 91(2), 249-256 (2008).

[63] Yong, Y. S., Aravazhi, S., Vázquez-Córdova, S. A., Carvajal, J. J., Díaz, F., Herek, J. L., García-Blanco, S. M. and Pollnau, M., "Temperature-dependent absorption and emission of potassium double tungstates with high ytterbium content," Opt. Express 24(23), 26825-26837 (2016).

[64] Wu, C. J., Chu, B. H. and Weng, M. T., "Analysis of optical reflection in a chirped distributed Bragg reflector," J. Electromagn. Waves Appl. 23(1), 129-138 (2009).

[65]Hong, J., Huang, W. and Makino, T., "On the transfer matrix method for distributed-feedback waveguide devices," J. Lightwave Technol. 10(12), 1860-1868 (1992).

[66] Makino, T., "Transfer matrix method with applications to distributed feedback optical devices," Prog. Electromagn. Res. PIER 10, 271-319 (1995).

[67]Björk, G. and Nilsson, O., "A new exact and efficient numerical matrix theory of complicated laser structures: properties of asymmetric phase-shifted DFB lasers," J. Lightwave Technol. 5(1), 140-146 (1987).

[68] Yariv, A., "Coupled-mode theory for guided-wave optics," IEEE J. Quantum Electron. QE9(9), 919-933 (1973).

[69] Ismail, N., Kores, C. C., Geskus, D. and Pollnau, M., "Fabry-Pérot resonator: spectral line shapes, generic and related Airy distributions, linewidths, finesses, and performance at low or frequency-dependent reflectivity," Opt. Express 24(15), 16366-16389 (2016).

[70] Purnawirman, Li, N., Magden, E. S., Singh, G., Moresco, M., Adam, T. N., Leake, G., Coolbaugh, D., Bradley, J. D. B. and Watts, M. R., "Wavelength division multiplexed light source monolithically integrated on a silicon photonics platform," Opt. Lett. 42(9), 1772-1775 (2017).

[71] Pollnau, M., Hardman, P. J., Kern, M. A., Clarkson, W. A. and Hanna, D. C., "Upconversion-induced heat generation and thermal lensing in Nd:YLF and Nd:YAG," Phys. Rev. B 58(24), 16076-16092 (1998).

[72] Saleem, M. R., Ali, R., Honkanen, S. and Turunen, J., "Thermal properties of thin $\mathrm{Al}_{2} \mathrm{O}_{3}$ films and their barrier layer effect on thermo-optic properties of $\mathrm{TiO}_{2}$ films grown by atomic layer deposition," Thin Solid Films 542, 257-262 (2013). 